\title{
A Catalogue of Marine Biodiversity Indicators
}

\section{OPEN ACCESS}

Edited by:

Marianna Mea,

Ecoreach srl, Italy and Jacobs

University of Bremen, Germany

Reviewed by:

Antoine Jean Grémare,

University of Bordeaux 1, France

Simone Libralato,

National Institute of Oceanography and Experimental Geophysics, Italy

*Correspondence: Heliana Teixeira

heliana.teixeira@ua.pt

${ }^{\dagger}$ Present Address: Heliana Teixeira

Departamento de Biologia and CESAM, Universidade de Aveiro, Aveiro, Portugal

Specialty section: This article was submitted to Marine Ecosystem Ecology, a section of the journal

Frontiers in Marine Science

Received: 24 June 2016 Accepted: 04 October 2016 Published: 04 November 2016

Citation:

Teixeira H, Berg T, Uusitalo L, Fürhaupter K, Heiskanen A-S,

Mazik K, Lynam CP, Neville S,

Rodriguez JG, Papadopoulou N, Moncheva S, Churilova T, Kryvenko O,

Krause-Jensen D, Zaiko A, Veríssimo H, Pantazi M, Carvalho S, Patrício J, Uyarra MC and Borja À

(2016) A Catalogue of Marine Biodiversity Indicators. Front. Mar. Sci. 3:207 doi: 10.3389/fmars.2016.00207

\begin{abstract}
Heliana Teixeira ${ }^{1 * t}$, Torsten Berg ${ }^{2}$, Laura Uusitalo ${ }^{3}$, Karin Fürhaupter ${ }^{2}$, Anna-Stiina Heiskanen ${ }^{3}$, Krysia Mazik ${ }^{4}$, Christopher P. Lynam ${ }^{5}$, Suzanna Neville ${ }^{5}$, J. German Rodriguez ${ }^{6}$, Nadia Papadopoulou ${ }^{7}$, Snejana Moncheva ${ }^{8}$, Tanya Churilova ${ }^{9}{ }^{10}$, Olga Kryvenko ${ }^{9,10}$, Dorte Krause-Jensen ${ }^{11}$, Anastasija Zaiko ${ }^{12,13}$, Helena Veríssimo ${ }^{14}$, Maria Pantazi ${ }^{15}$, Susana Carvalho ${ }^{16}$, Joana Patrício ${ }^{1}$, Maria C. Uyarra ${ }^{6}$ and Àngel Borja ${ }^{6}$

${ }^{1}$ D.2 Water and Marine Resources Unit, European Commission, Joint Research Centre, Directorate for Sustainable Resources, Ispra, Italy, ${ }^{2}$ MariLim Aquatic Research GmbH, Schönkirchen, Germany, ${ }^{3}$ Marine Research Centre, Finnish Environment Institute, Helsinki, Finland, ${ }^{4}$ Institute of Estuarine and Coastal Studies, University of Hull, Hull, UK, ${ }^{5}$ Centre for Environment, Fisheries \& Aquaculture Science, Lowestoft, UK, ${ }^{6}$ AZTI-Tecnalia, Marine Research Division, Pasaia, Spain, ${ }^{7}$ Hellenic Centre for Marine Research, Institute of Marine Biological Resources and Inland Waters, Heraklion Crete, Greece, ${ }^{8}$ Department of Marine Biology and Ecology, Institute of Oceanology-Bulgarian Academy of Sciences, Varna, Bulgaria, ${ }^{9}$ Department of Biophysical Ecology, Kovalevsky Institute of Marine Biological Research of RAS, Sevastopol, ${ }^{10}$ Department of Oceanographic Processes Dynamics, Marine Hydrophysical Institute of RAS, Sevastopol, "11 Department of Bioscience, Aarhus University, Silkeborg, Denmark, ${ }^{12}$ Marine Science and Technology Centre, Klaipéda University, Klaipéda, Lithuania, ${ }^{13}$ Coastal and Freshwater Group, Cawthron Institute, Nelson, New Zealand, ${ }^{14}$ Faculty of Sciences and Technology, MARE Marine and Environmental Sciences Centre, University of Coimbra, Coimbra, Portugal, ${ }^{15}$ Hellenic Centre for Marine Research, Institute of Marine Biological Resources and Inland Waters, Athens, Greece, ${ }^{16}$ Red Sea Research Center, King Abdullah University of Science and Technology, Thuwal, Saudi Arabia
\end{abstract}

A Catalogue of Marine Biodiversity Indicators was developed with the aim of providing the basis for assessing the environmental status of the marine ecosystems. Useful for the implementation of the Marine Strategy Framework Directive (MSFD), this catalogue allows the navigation of a database of indicators mostly related to biological diversity, non-indigenous species, food webs, and seafloor integrity. Over 600 indicators were compiled, which were developed and used in the framework of different initiatives (e.g., EU policies, research projects) and in national and international contexts (e.g., Regional Seas Conventions, and assessments in non-European seas). The catalogue reflects the current scientific capability to address environmental assessment needs by providing a broad coverage of the most relevant indicators for marine biodiversity and ecosystem integrity. The available indicators are reviewed according to their typology, data requirements, development status, geographical coverage, relevance to habitats or biodiversity components, and related human pressures. Through this comprehensive overview, we discuss the potential of the current set of indicators in a wide range of contexts, from large-scale to local environmental programs, and we also address shortcomings in light of current needs. Developed by the DEVOTES Project, the catalogue is freely available through the DEVOTool software application, which provides browsing and query options for the associated metadata. The tool allows extraction of ranked indicator lists best fulfiling selected criteria, enabling users to search for suitable indicators to address a particular biodiversity component, ecosystem feature, habitat, or pressure in a marine area of interest. This tool is useful for EU Member States, 
Regional Sea Conventions, the European Commission, non-governmental organizations, managers, scientists, and any person interested in marine environmental assessment. It allows users to build, complement or adjust monitoring programs and has the potential to improve comparability and foster transfer of knowledge across marine regions.

Keywords: assessment, non-indigenous species, food webs, seafloor integrity, pressures, Marine Strategy Framework Directive

\section{INTRODUCTION}

Taking the pulse of natural ecosystems and tracking progress toward environmental goals requires suitable indicators (e.g., Pereira et al., 2013; Tittensor et al., 2014; Geijzendorffer et al., 2015). Worldwide, there are several marine biodiversity conservation initiatives in place demanding robust and scientifically-based environmental assessments. Among the most comprehensive and with relatively wide geographical scope are the EU Marine Strategy, the US National Ocean Policy, the United Nations (UN) Convention on Biological Diversity (CBD), or the Convention on the Law of the Sea. Also at regional and local scales, environmental objectives have long been set to cope with the impacts of human activities in marine waters (e.g., Regional Sea Conventions; HELCOM, 2009; Long, 2012) and to protect natural capital (e.g., Marine Protected Areas policies; Costanza et al., 1997; Agardy et al., 2011; Liquete et al., 2013). These initiatives are increasingly important now, as the seas are facing a "marine Wild West" rush (Cressey, 2016) steered by blue growth prospects worldwide, which will inevitably increase and diversify anthropogenic pressures in our oceans (Børresen, 2013; Gramling, 2014). Nations must therefore act quickly to prevent the accelerated depletion of natural resources and wildlife (McCauley et al., 2015; Cressey, 2016), especially since there is still a lack of understanding on many aspects of our marine ecosystems (Danovaro et al., 2014; EEA, 2014).

The success of management is partially dependent on the availability of scientific tools to managers (Rist et al., 2013; Knights et al., 2014). Robust indicator selection, transparent use of information, and effective communication of results constitute crucial parts of this process, but the development, calibration and validation stages of new indicators and assessment approaches can compromise timely managerial response (Borja and Dauer, 2008). However, there is still a common practice of developing new indicators for each new assessment initiative put forward as well as for any specific case or policy requirement. Indeed, during the last couple of decades we have witnessed a boom of ecological indicators worldwide (see reviews by e.g., Marques et al., 2009; Cardoso et al., 2010; Birk et al., 2012; Borja et al., 2016a), driven either by environmental policies or research, attempting to cover, for example, the most sensitive habitats and endangered organisms (e.g. Gobert et al., 2009; Waycott et al., 2009; Deter et al., 2012; Gatti et al., 2015), or to detect imminent threats to ecosystems (Halpern et al., 2012; Katsanevakis et al., 2016) and their services (Liquete et al., 2013).

Although there is still a lack of practical indicators regarding many aspects of the marine ecosystem (Berg et al., 2015; Hummel et al., 2015; Piroddi et al., 2015), and dedicated research is still needed (Rudd, 2014), it is also recognized that the cost and delays associated with gathering information, learning and development process are often responsible for failures encountered in the implementation stage of management plans (Lee, 1999 in Rist et al., 2013; Pitcher et al., 2009). All this has inspired recent attempts to take advantage of the existing knowledge and past efforts to develop robust assessment tools and optimize their use in fulfilling stakeholders' environmental commitments (e.g., Cardoso et al., 2010; Fautin et al., 2010; Zampoukas et al., 2012; Liquete et al., 2013; Pereira et al., 2013; Tittensor et al., 2014; Berg et al., 2015).

Efficient adoption of the existing knowledge not only accelerates the developmental process per se (e.g., Fautin et al., 2010; Teixeira et al., 2012; Borja et al., 2015) but also implies that data associated with indicator development and subsequent monitoring should be available to some extent. This can be valuable when baselines and spatio-temporal trends need to be established locally, regionally or even globally (Muxika et al., 2007; Duffy et al., 2013; Probst and Stelzenmüller, 2015; Borja et al., 2016b). A major difficulty in producing a coherent picture of the current status and trends of marine diversity is the lack of standardized and coordinated approaches for monitoring it (Duffy et al., 2013). Recently, many conservation initiatives have recognized this and started building their marine strategies (e.g., Zampoukas et al., 2012) or recommendations (e.g., Duffy et al., 2013; Pereira et al., 2013) upon relevant existing activities to promote comparability within and across regions.

An important obstacle to the adoption and effective use of existing tools is the tedious and time consuming task of searching candidate indicators scattered throughout the vast scientific, technical and often also gray literature, along with the need to compare among methods every time a new management plan needs to be set. The idea of collating scattered indicators in order to establish the integrity and biodiversity trends of marine ecosystems is therefore not only very appealing but also much needed and wise (Duffy et al., 2013). By reducing the time spent searching for indicators and by optimizing the comparison between different approaches, time can be devoted to other crucial aspects. For example, the uncertainty associated with assessments, or the effective communication of results, which are too often neglected when applying indicators in assessment and regulatory contexts (Rees et al., 2008; Queirós et al., 2016).

With the European Marine Strategy Framework Directive (MSFD, 2008/56/EC) as scenario, we evaluated the current potential of existing ecological indicators to support the assessment of marine biodiversity and address environmental targets (Berg et al., 2015). The MSFD is a good test of the capability of current indicators as it adopts an ecosystem-based 
approach that considers 11 broad range descriptors to describe the environmental status of marine waters. These descriptors encompass both state and pressure features, from biological diversity and food webs to contaminants and marine litter.

The primary aim of our study was to identify indicators capable of supporting the assessment of four descriptors (D) sensu MSFD: biological diversity (D1), non-indigenous species (D2), food webs (D4), and seafloor integrity (D6). We present a catalogue containing numerous indicators and respective metadata available as a database through the DEVOTool free software application. This tool enables users to browse the catalogue and extract lists of fit-for-purpose indicators using various selection criteria and ranking options.

The concepts of indicator and index are often used as synonyms but it is important to clarify that in a regulatory context indicator may be a proxy for something different from what it actually measures (Rees et al., 2008). An indicator is intended to highlight the status of the system and, for e.g., the European Environmental Agency recognizes distinct types of indicators depending on what they address: descriptive indicators, performance indicators, efficiency indicators, and total welfare indicators (Smeets and Weterings, 1999). The term should therefore be distinguished from index, an aggregation of indicators into a single representation (Rees et al., 2008). Indices are considered as one possible measure of the systems status, as they relate to a specific qualitative or quantitative feature of the system (Pinto et al., 2009). The selection of key indicators, effective at capturing the system condition and announcing changes compared to the specified objectives, leads then to the elaboration of an assemblage of relevant indices used as operational tools. However, in this manuscript, we use the term "indicator" to refer to what is commonly called an index or assessment system, i.e., a qualitative or numerical expression or a statistic, reflecting an ecosystem feature or magnitude of anthropogenic pressure (Claussen et al., 2011; Berg et al., 2015). This is to ensure some coherence with the MSFD, where the term is used for the metrics needed for baseline assessments and to monitor whether environmental targets have been met.

The analysis of the marine biodiversity indicator catalogue aimed: (i) to identify the strengths and gaps in the existing sets of indicators in order to direct the further development of indicators toward the most urgent needs; and (ii) to foster transfer of knowledge across countries and marine regions, so that indicators operational in one area could be easily adjusted and adopted elsewhere for the environmental assessments.

This review highlights the main attributes of the indicators contained in the catalogue, namely the biodiversity components they address and habitats they apply to, their geographical coverage and potential for addressing relevant pressures. We also describe the type of data behind the indicators and their status of development. Moreover, we discuss the potential of existing marine biodiversity indicators in the context of global biodiversity observation networks that could form the basis for worldwide monitoring programs (Pereira et al., 2013; GOOS, 2016). Finally, we provide recommendations on research priorities for improving quality of the assessment tools.

\section{MATERIALS AND METHODS}

\section{Compilation of Indicators: Survey Design and Scope}

Our survey (conducted in mid-2013) targeted marine indicators with potential to address biological diversity, trends and impacts of non-indigenous species, food webs' properties, and seafloor integrity. A questionnaire for retrieving indicators and associated metadata was circulated among 20 scientists from 14 institutions, identified in the database by a "contributor code". All contributors were either involved in the implementation of the MSFD or having broad knowledge on indicators' development or application in their respective regions or fields of expertise.

The information on indicators was compiled from very different sources in national and international environmental contexts: EU Directives, Regional Seas Conventions (RSC), assessments from non-EU seas, and other regional research programs. Since the primary goal of building this Catalogue of Indicators (Supplementary Material S1) was to assist the implementation of the MSFD in Europe, the first sources of information were programs associated with existing EU legislation. In particular we screened indicator proposals under the Water Framework Directive (WFD, 2000/60/EC), the Nature Directives (Habitats Directive-HD, 92/43/EEC and Birds Directive-BD, 2009/147/EC), and other relevant EU legislation (including the Common Fisheries PolicyCFP: Council Regulation (EC) No 199/2008; Commission Decision 2010/93/EU). These EU programs link directly to the biodiversity related descriptors in the MSFD. For the WFD indicators, the survey was primarily based on the WISER project methods database (Birk et al., 2012) (available at http://www.wiser.eu/results/method-database/). Any updates to indicators, since the WISER database, have been included in the current catalogue; for example, after subsequent WFD Intercalibration results (Carletti and Heiskanen, 2009; Commission Decision 2008/915/EC; Commission Decision $2013 / 480 / \mathrm{EU})$, or after further revisions of the methods by their authors. Approaches developed in the framework of RSC covering European seas were also taken into account, namely those by HELCOM-Baltic Marine Environment Protection Commission-Helsinki Commission, the OSPAR Convention for the Protection of the Marine Environment of the North-East Atlantic, the Barcelona Convention - UNEPMAP Mediterranean Action Plan, and to a lesser extent the Bucharest Convention-Black Sea Commission. Effort was also made to include the indicators used by Member States in their MSFD reporting on Initial Assessments, Good Environmental Status, Environmental targets and associated indicators, if available in the EU Eionet Central Data Repository (http://cdr.eionet.europa.eu/recent_etc?RA_ID=608) or if provided by national researchers. Indicators developed and used in other contexts, i.e., from research or monitoring programs within Europe, but also further afield (e.g., the Red Sea area or in the USA), as well as information published in broader scientific literature, were also included in the catalogue. The first version of the catalogue has been released in January 2014 (version 6) and a recent update was completed in March 2016 
(version 7). As a result of this consultation, over 700 literature references have been compiled and made available through the "Sources" field of the database (Supplementary Material S1). New developments since our survey may not be represented in the catalogue. For example, work and advances that ICES working groups have been following on food webs (D4) and seafloor integrity (D6) fields of research are a relevant and complementary source of information (ICES, 2014, 2015b).

\section{Catalogue Structure}

The catalogue contains three main sections: "Indicators," "Metadata," and "Sources," composed of both open and closed fields for reporting information. A fourth section allows performing "Analyses" such as querying the database. The "Indicators" section has ten fields describing intrinsic properties of the indicator and other related information: indicator name, RSC affiliation, indicator description, data requirements, collection method, associated costs, overall indicator status, unit, confidence or uncertainty of the indicator, observations or remarks.

The "Metadata" section has two main types of fields. There are fields linked to MSFD requirements for reporting descriptor coverage, i.e., to assign the relation to the 11 MSFD descriptors, and to relate indicators with the Commission Decision criteria and indicators (COM Dec 2010/477/EU) specifically for descriptors D1, D2, D4, and D6. Other fields allow specification of targets of the indicator in terms of biodiversity components (e.g., phytoplankton, macroalgae, fish), and a set of predominant ecotypes (e.g., pelagic fish, demersal fish) for mobile components, as well as the option to insert any taxonomical specificity of the indicator (i.e., taxon name). There are also fields for reporting the link to pressures such as physical damage, contamination pressures including organic enrichment, marine litter, introduction of pathogens or non-indigenous species, extraction of living resources, underwater noise, and marine acidification. Finally, other fields specify settings for applying the indicator, ultimately including information on targets and/or reference conditions for the indicator, associating them to particular habitat(s) where it applies (i.e., seabed, water column, and ice-associated), and its geographical coverage such as e.g., the EU MSFD marine region(s) or non-EU seas where it has been used (with further specification of the scale of application within marine sub-regions, subdivisions or ecological areas, and subareas). Also within settings, it is possible to associate indicators to country level or establish correspondence to existing monitoring programs or initiatives, such as International Conventions, RSC, EU Directives, National monitoring or Research program. If there is data availability for an indicator, such details (e.g., time series and GIS data) and a link to source can also be provided. Finally, within all sections, source fields link certain attributes to specific literature, and all references are then made available in the section "Sources." Further details on the fields and definitions of categories can be found in the database (Supplementary Material S1) and in Teixeira et al. (2014).

\section{Data Analysis}

The analysis presented in this review is based on the Catalogue of Indicators database version 7 (Supplementary Material S1) available through the DEVOTool 0.64 software application (free download at: http://www.devotes-project.eu/devotool/), allowing navigation of the database. The catalogue was explored using the query functions available in the "Analyses" section of this software (see DEVOTool-manual-0.64).

To provide a better overview and summarize the content of the catalogue, the indicators reported in the survey were classified a posteriori according to four criteria: (i) allocation to a "DPSIR stage" within the DPSIR framework (DriversPressures-State Change-Impacts-Responses, Elliott, 2002; Smith et al., 2016) and following Berg et al. (2015); (ii) in relation to their "Main attribute" or theme addressed; (iii) according to the type of data required to calculate the index i.e., "Underlying variable type"; and (iv) according to its classification or "Algorithm type". These fields were also included in database vs.7 and definitions of categories are provided as Supplementary Material S2.

Flow diagrams were built with RAW 1.0.2 developed by DensityDesign http://raw.densitydesign.org.

\section{RESULTS}

\section{General Overview of Indicators' Characteristics and Scope}

The catalogue currently contains 611 indicators, of which about half are operational, i.e., tested and validated, with associated target values or classification boundaries, easily interpretable within a good through bad environmental status continuum to be useful under regulatory contexts (Figure 1). A significant proportion of the indicators (36\%) are still under development, i.e., the indicator proposal exists but, for example, has not yet been validated with real data or is in the process of calibration for use in new locations or habitats. A small percentage of conceptual indicators, i.e., an indicator idea supported by theoretical grounds, although no practical measure or metric is yet available, were also reported (7\%).

Most of the entries in the catalogue are state indicators that report on distinct aspects of the ecosystem. Habitat integrity is the most widely used feature to assess the health of the marine ecosystem (26.4\%, Figure 2). Indicators in this category focus on the biotope relevant features, considering the physical habitat and associated biological communities. That is, they use abiotic or biotic data, such as hydrological and physical-chemical indicators, abundance or biomass of habitat-forming taxa, and very often their spatial distribution. In many cases, they integrate different information, using more than one variable type, sometimes up to six different categories of data (Figure 2). For example, the "COralligenous Assessment by ReefScape Estimate index" uses abiotic data, abundance, physio-/morphological data, spatial distribution, taxonomic, and traits composition (Gatti et al., 2015).

The status of the marine environment is also assessed using the biota, from the sub-individual level, to the species and community levels, and to the ecosystem level. That is achieved by 


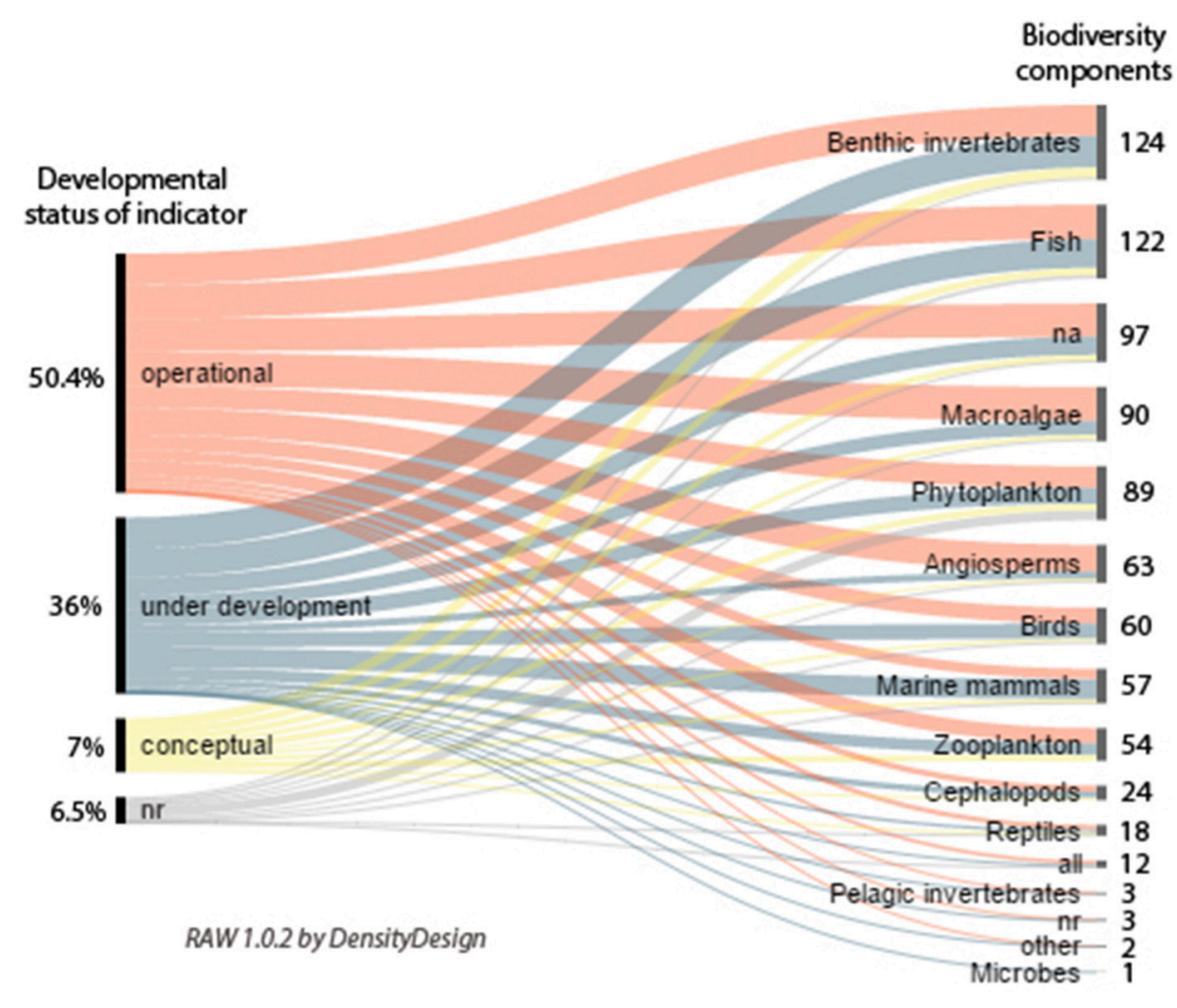

FIGURE 1 | Developmental status of the indicators in the DEVOTool Catalogue (database version 7) and number of indicators available per biodiversity component. Some indicators may apply to more than one biodiversity component, either taking several components simultaneously or interchangeably (i.e., total column sum > 611 indicators). 97 indicators in the catalogue do not target biodiversity components (na). 6.5\% indicators with no reported status (nr).

focusing on aspects of community structure, population ecology, production and trophic relations, using indicator species or target groups, accounting for species life traits, or measuring the physiological condition of individuals (Figure 2).

Although the number of indicators differs conspicuously between biodiversity components (Figure 1), there is a good coverage of the major taxonomic groups required by the MSFD. With the exception of microbes, all are covered by operational indicators. For microbes, only one indicator, still under development, has been reported ("Abundance of bacterioplankton"). Benthic invertebrates and fish have by far the greatest number of related indicators ( $>100$, Figure 1). Pelagic species are the least assessed by the available indicators, with only eight indicators for fish and two for elasmobranchs. Also pelagic macroinvertebrates are much less covered compared to benthic ones. Angiosperms and macroalgae, birds, marine mammals, and phyto- and zooplankton are addressed by a considerable number of indicators, while reptiles and cephalopods have a comparably lower number. Finally, independently of their taxonomic group, fauna from extreme habitats, such as deep sea or ice-associated habitats, are, in general, very poorly covered by the current set of indicators. From the reported indicators, only the "Marine Biological Valuation Methodology" and the "Biopollution Level index" accommodated those organisms (together with all other faunal groups) in a broad environmental assessment of the area.
These indicators target larger trends, without the intention of focusing on group specific properties.

Over 400 indicators have been developed specifically for a biodiversity component or subcomponent, and the catalogue makes reference to more than 80 different species for which indicators exist. Six of them are threatened marine species (Clangula hyemalis, Melanitta fusca, Monachus monachus, Polysticta stelleri, Squalus acanthias, Thunnus thynnus) included in the Red List of the International Union for Conservation of Nature and Natural Resources (IUCN). Other indicators may not be specific to a single component $(n=86)$ but rather, target several groups either simultaneously or interchangeably, resulting overall in more indicators targeting biodiversity components than indicator entries in the catalogue as shown in Figure 1 (sum of indicators per biodiversity component = $819 ;>611)$. Indicators may also address biodiversity components in a broader and more encompassing way by focusing on, for example, the processes between certain levels of the ecosystem (like "Energy flows and transfer efficiencies among trophic levels or functional groups") or groups defined independently of biodiversity components (e.g., "Number of biocenosis/facies"). In these cases no specific link to a biodiversity component has been reported. Ninety seven indicators do not target biodiversity components directly, focusing instead on biotope features beyond the biological characteristics, or addressing 


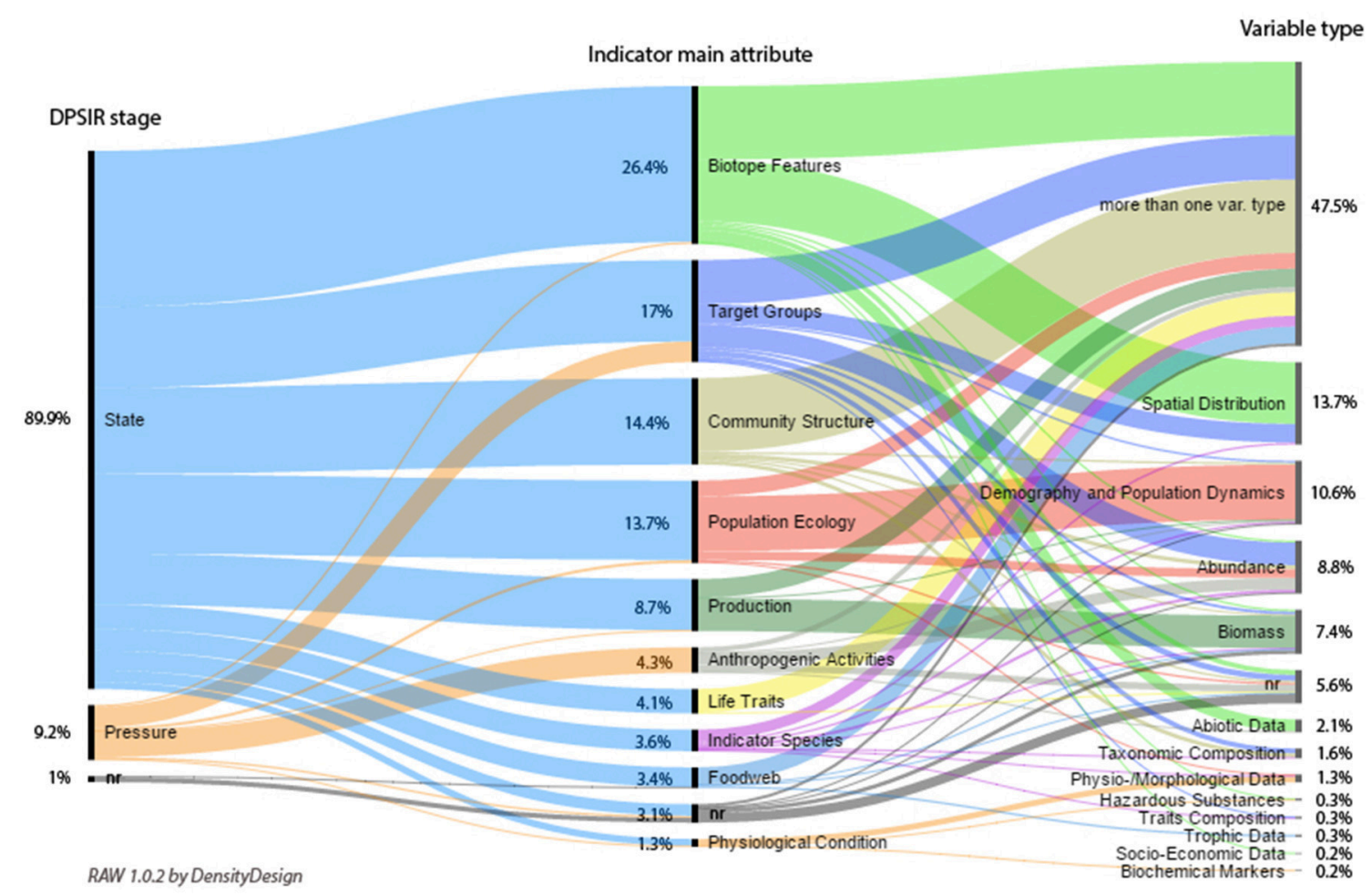

FIGURE 2 | Type of indicators in the DEVOTool Catalogue (database version 7). Stage of the indicators in the DPSIR cycle (1\% indicators with no reported DPSIR stage-nr), their main attribute (3.1\% indicators with no information reported), and the type of data required to calculate them (variable type; $5.6 \%$ indicators with no information reported).

anthropogenic activities, e.g., "Areal extent of protected areas," "Depth of sediment redox potential discontinuity," or "Number of dredging permits and the amount dredged related to them".

Only $9 \%$ of the entries in the catalogue are pressure indicators (Figure 2), essentially focusing on anthropogenic activities (e.g., "Ballast water treatment indicator," "Seafloor exploitation index," or species removal and by-catch indicators), specific target groups (mainly related with trends in non-indigenous species introduction) or biotope features (e.g., "Light pollution for sea birds").

Habitats have been linked to 446 indicators, about half of which are operational (54.5\%). Seabed habitats are represented by a higher number of indicators than water column (298 vs. 178), and no indicator was reported for ice-associated habitats. A great part of the seabed indicators report on issues related to spatial distribution of benthic habitats (e.g., "Areal extent of rocky habitats," "Distributional range of circalittoral and bathyal soft bottom habitats"), or target habitat structuring and forming species (e.g., "Posidonia oceanica Rapid Easy Index," "Population structure of long-lived macrozoobenthic species"), or address benthic communities structural status (e.g., "M-AMBI"). There are also several indicators addressing anthropogenic activities' pressures to the seabed $(n=17)$. If we distinguish seabed indicators according to the bottom type (hard bottom-rock and biogenic reef; soft bottom-sand, mud and sediment; mixed bottom-mixed and coarse sediment), the overall number of indicators relevant to hard bottom is lower than for soft bottom, but the number of indicators specifically addressing hard bottom is, however, higher. Regarding depth zone [littoral, shallow sublittoral, shelf, bathyal (upper and lower), and abyssal], the number of indicators decreases noticeably from shallow to the deep sea, and there are no indicators exclusively addressing abyssal or bathyal zones. Only four indicators are specific for the shelf zone. Water column habitat is represented by indicators mainly targeting pelagic groups, population ecology and the structure of their communities, production, and biotope features (e.g., "Abundance or biomass of key species in the coastal waters," "Secchi depth," "Trends in populations of large pelagic fish," or "Chl a concentration").

Most of the indicators in the catalogue have simple algorithms and methods of calculation when integrating the data $(77.7 \%)$, using categorical approaches, simple arithmetic or statistics. Only $3.9 \%$ of them demand higher expertise or IT capabilities for calculations.

More than half $(62.7 \%)$ of the indicators reported as operational fail to report specific targets, boundaries or reference levels associated with their use or even mention the possibility of setting them. The 115 indicators that report such information often associate targets or boundaries to specific regions, habitats, species or even methodological aspects. In a few cases they 
refer to the existence of targets alongside sources but without presenting them.

A majority of the indicators also lack any measure of confidence or uncertainty associated with their assessment results. When reported (6.7\%), uncertainty assessments were essentially taking into account sampling effort variation, sampling error measurement or spatial and temporal variation; only a couple of examples performed sensitivity tests to the index parameters through evaluation of the stochastic variation of those variables; and, in one case, a set of requirements for index application was established to ensure some minimum robustness but without providing any measure of confidence of the final estimates.

\section{Capability to Address Pressures}

The current indicator set gathers a great diversity of approaches capable of addressing the main pressures listed by the MSFD (Figure 3). Most of the indicators address nutrient and organic matter enrichments, which reflect eutrophication that is still the most widespread pressure in marine and coastal waters in Europe (EEA, 2013, 2015). There are also a number of policies targeting eutrophication, and a large number of indicators have been developed to display whether these policies have resulted in improvement of the eutrophication status (Ferreira et al., 2011). Likewise, many of the indicators were sensitive toward organic loading, which reflects the high number the benthic invertebrate indicators that generally reflect the status of benthic habitats with respect to organic loading. A second pressure group that was targeted by a high number of indicators was related to physical loss, interference with hydrographical processes, and physical damage to marine habitats. These reflect the abrasion pressures caused by demersal fishing and aggregate dredging, but also silting, smothering, and increase of turbidity due to coastal and underwater constructions (e.g., Knights et al., 2013; Oesterwind et al., 2016; Smith et al., 2016). A third group of indicators are able to reflect the effects caused by contamination and fishing (i.e., removal) pressures. Pressures that have been identified recently such as marine noise, litter or acidification, and pressures such as extraction of seaweeds and maerl are addressed by the lowest numbers of indicators.

\section{Geographical Coverage}

Most of the entries in the catalogue are linked to at least one marine region. There are some exceptions regarding conceptual and under development indicators that have not yet been tested with regional data sets, or indicators whose conceptual basis makes them potentially applicable to any region (e.g., "BTABiological Traits Analysis" or "Strength of bottom-up cascade in marine size spectrum").

The catalogue contains indicators developed and in use under diverse contexts within Europe but also beyond Europe's geographical area (e.g., in the Red Sea area or in the USA), corresponding to marine areas of 34 different countries (Figure 4). Despite this wide coverage, a good description of methods' availability can only be guaranteed for the European regional seas (Baltic Sea, Black Sea, Mediterranean
Sea, and North-East Atlantic Ocean) and their respective marine regions. The number of indicators differs markedly between regional seas (Figure 4), partly reflecting the size and overall biodiversity pattern of the specific regional seas but also the focus of environmental concern and research tradition. For example, Mediterranean ranked highest of the European Seas for the state-of-knowledge index across taxa (Costello et al., 2010) suggesting that the effort for taxonomic description of species has been in historical focus rather than development of environmental indicators for biodiversity assessment purposes. On the other hand, despite the low biodiversity of the Baltic Sea, in comparison to fully marine areas with higher salinity, and despite the gaps in taxonomical description of certain organism groups (Ojaveer et al., 2010), a considerably high number of indicators have been reported to this region. This reflects that environmental status concerns and the governments' corresponding long-term investment policy in biodiversity research have been considered for a long time.

\section{DISCUSSION}

One of the aims of this catalogue is to promote the coherent use of data and the adoption of compatible metrics and indicators, in line with several policy requirements (Zampoukas et al., 2012; Pereira et al., 2013; GOOS, 2016). In fact, despite that the focus of conservation initiatives worldwide might differ, they often share common assessment elements and make use of similar baseline information (e.g., Duffy et al., 2013; Pereira et al., 2013). The majority of indicators in the catalogue are already associated with at least one specific assessment system or monitoring program, and in many cases, they are linked to more than one. Approximately $30 \%$ of the indicators reported are already used by other EU Directives or regulations (Nature Directives, Water Framework Directive or Common Fisheries Policy). Many are used by national monitoring programs or within international agreements and Regional Sea Conventions. This shows the great potential for their application across policies, spatial scales, and geographic regions.

Essential metrics for monitoring global trends in biodiversity and the integrity of the oceans worldwide (Pereira et al., 2013; GOOS, 2016) such as, for example, "Taxonomic diversity," "Habitat structure," "Allelic diversity," "Phytoplankton biomass and productivity," "Incidence of harmful algal blooms," "Zooplankton diversity," "Fish distribution and abundance," "Apex predator distribution and abundance," "Seagrass cover," "Macroalgal cover," and "Live coral cover," are largely covered by operational indicators in the catalogue. This reinforces the opportunity for incorporation of existing knowledge and tools in new marine conservation programs.

The set of indicators compiled can essentially be used within two stages of the DPSIR cycle: To measure pressures $(\mathrm{P})$ on the natural system and to assess changes in its state (S), i.e., the properties and processes of the ecosystem (Berg et al., 2015). However, the catalogue contains by far more indicators that 


\section{Indicators per pressure type}

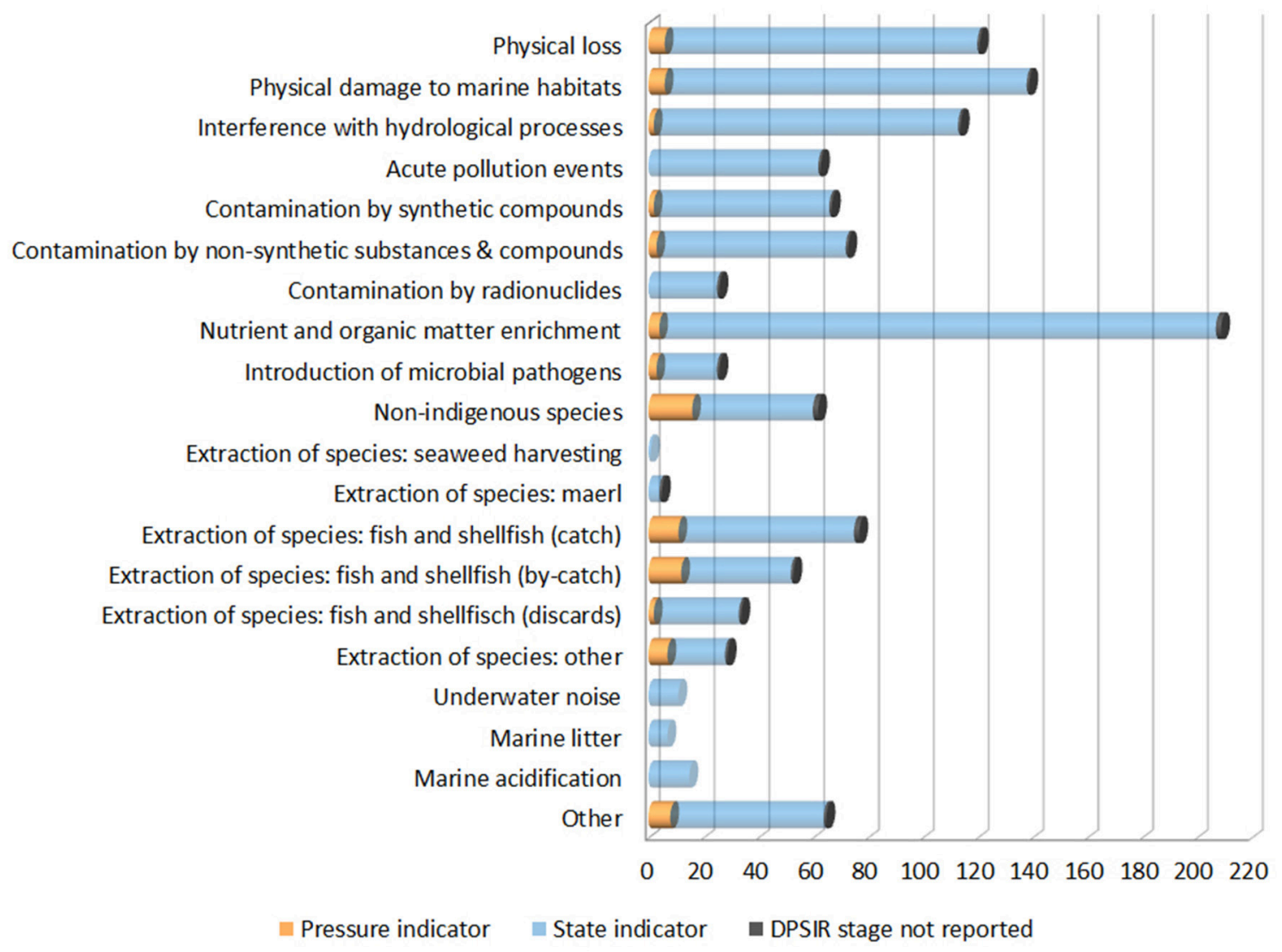

FIGURE 3 | Number of indicators reported per pressure type, with indication of the DPSIR stage the indicators refer to: Pressure or State. Pressure types follow the Marine Strategy Framework Directive list of pressures (Annex II).

primarily measure the response of ecosystems to pressures than pressures themselves. This is explained by the fact that the MSFD descriptors targeted here were essentially biodiversity-related ones, which encompass very few pressure requirements.

The adequacy of the current set of indicators to address the requirements of the MSFD has been exhaustively analyzed by Berg et al. (2015). Here we focus on the capability and current knowledge on marine biodiversity indicators to support ecosystem-based approaches (Borja et al., 2016a) and on how indicator gaps may compromise such endeavors (Hummel et al., 2015). We discuss this at several levels: (i) in relation to biodiversity components and habitats; (ii) with regard to relevant pressures on the marine environment; (iii) considering the survey and coverage of the catalogue; and (v) in relation to the status of development of the indicators and most common weaknesses of these methods.

\section{Biodiversity Components and Habitats}

The availability of indicators per biodiversity component may reflect the species richness of the group, their economic importance, the conservation status of the component or the level of taxonomic knowledge and expertise available. The fewer species exist in a group, or the more restricted their distribution is (e.g., cephalopods or reptiles), the smaller the number of indicators reported. A higher number of indicators, besides driven by high species richness, wide distribution, and environmental hazards related to those (e.g., phytoplankton nuisance blooms and HABs), may also reflect their important function in the food web and in the nutrient cycling (e.g., benthic invertebrates), as well as the economic importance of the biodiversity component (e.g., commercial fish). The relatively high number of marine mammal and bird indicators may instead reflect the high conservation status of these components and their importance as flagship species (Smith et al., 2014), prompting efforts toward their monitoring and protection internationally. In contrast, angiosperms and macroalgae species are seldom protected as species per se but they are often protected as structuring components of biotopes/habitats, which might also explain the great availability of indicators. Like the benthic invertebrates, also zooplankton is high in species richness, as well as in abundance, and forms an important link in many food webs and nutrient cycles. Nevertheless, the number of indicators reported for zooplankton is relatively low compared to phytoplankton. One of the reasons could be the absence of 


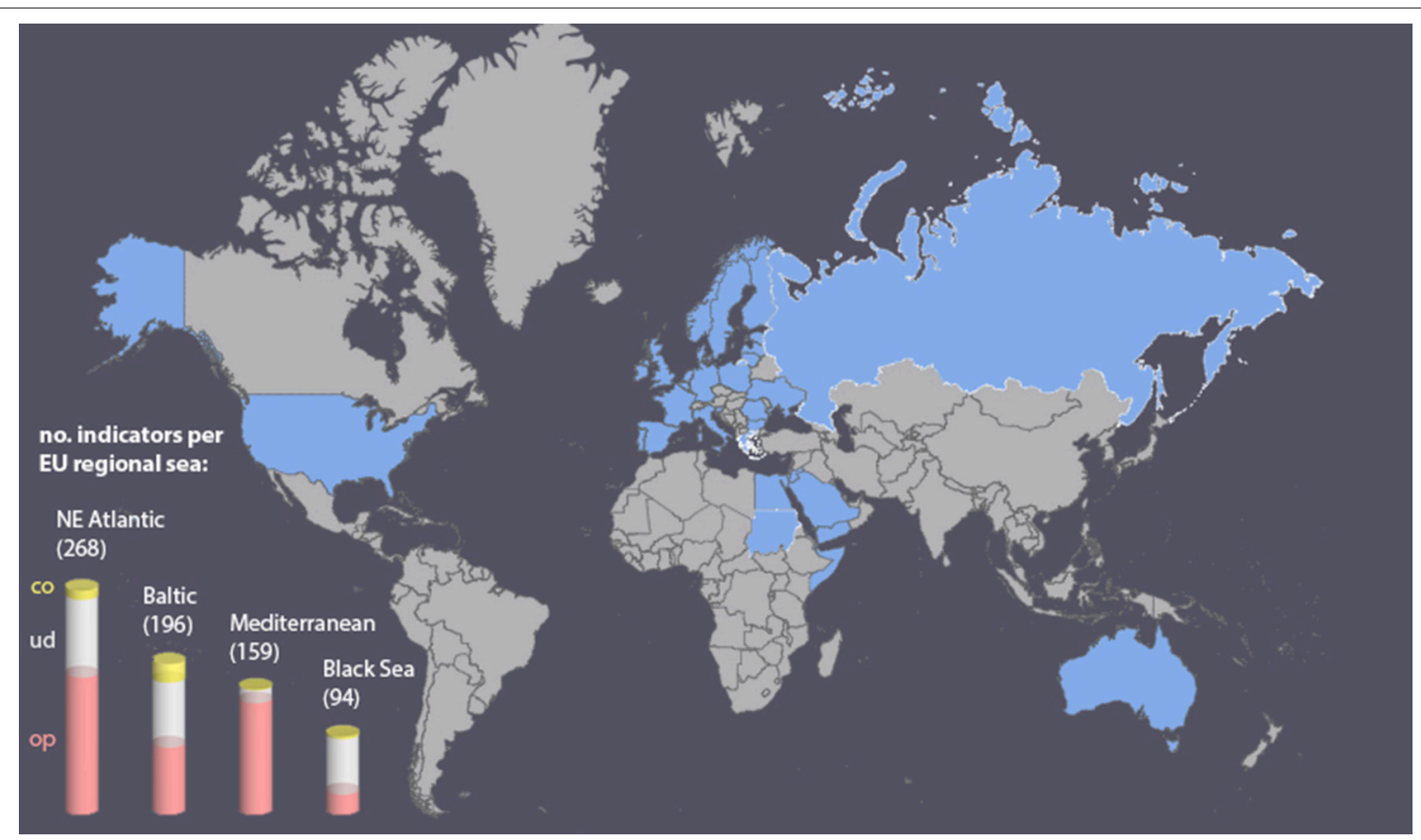

FIGURE 4 | Number of indicators available per European regional sea (either operational-op, under development-ud, or conceptual-co). The map highlights countries associated with indicator entries in the catalogue $(n=34)$ : Australia, Belgium, Bulgaria, Cyprus, Denmark, Djibouti, Egypt, Estonia, Finland, France, Germany, Greece, Ireland, Israel, Italy, Jordan, Latvia, Lithuania, Netherlands, Norway, Poland, Portugal, Romania, Russian Federation, Saudi Arabia, Slovenia, Somalia, Spain, Sudan, Sweden, Ukraine, United Kingdom, United States, Yemen.

this component in the EU Water Framework Directive, not stimulating further development of methods to assess its status.

Marine habitats are also covered differently by the indicators available. The higher proportion of operational indicators for seabed in comparison to water column habitats might be partially explained by the longer tradition in monitoring and status assessments of benthic communities (Díaz et al., 2004) and also because they are easier to conduct and interpret compared to the strongly spatially variable and stochastic water column communities. The lack of ice-associated habitat indicators may result from an unclear or misleading definition and classification for those habitats and their related communities, but also from their restricted temporal-spatial extend within EU seas. Two indicators relevant to ice habitats exist in the Baltic but refer to gray seal pupping: "Number of pups of gray seals" and "Abundance of seals (at haul-out sites and within breeding colonies)" (HELCOM, 2013). Thus, they are not directly assigned to the habitat type, as both are targeting a specific species. The reduced number of indicators applicable to the deep-sea habitats is mainly related to the degree of access, until recently limited (Danovaro et al., 2014). As shallow depth zones are easy to reach, they consequently have a longer tradition of surveillance and more comprehensive datasets are available, allowing indicator development. The lack of indicators specifically addressing the bathyal and abyssal zone, and in particular the pelagic domain, can be regarded as an important gap in the current suite of indicators. These zones host characteristic communities and species, entangled within unique ecological processes that require specific sampling and assessment approaches (Costello et al., 2010; Danovaro et al., 2014; Thurber et al., 2014; Rogers, 2015) and, therefore, specific indicators for assessing their status. However, an understanding of deep-sea processes needs to be further developed along with baselines for several parameters, before sensitivity metrics can be incorporated into indicator approaches. This is indispensable to allow following the multiple pressures and impacts from increasing offshore activities and climate change (Gramling, 2014; Levin and Le Bris, 2015).

Considering the main topics addressed by the indicators, our review highlights the need for further development and validation of indicators that inform: On the ecosystem level (addressing structure, processes, and functions), on the genetic diversity, on the effects of non-indigenous invasive species and quantification of their impacts, along with indicators informing on food webs structure and functioning, particularly encompassing lower trophic levels, which are currently poorly addressed. These findings concur with others (e.g., Geijzendorffer et al., 2015; Hummel et al., 2015) who demonstrate that decision-makers are currently constrained by the lack of data and indicators on changes in genetic composition, species populations, and ecosystem function and structure. At the ecosystem level the current set of indicators can be effectively complemented by modeling approaches and their modelderived indicators, in particular for topics such as food webs, connectivity, and the effects of non-indigenous species on the ecosystems (see Piroddi et al., 2015; Tedesco et al., 2016). Functional aspects lag behind in operational indicators, but the 
recent insights in biodiversity and ecosystem function (BEF) relationships may soon contribute to the use of BEF relationships within ecosystem functioning monitoring (Mouillot et al., 2013; see review by Strong et al., 2015). Recent developments on emerging molecular-based indicators are expected to evolve rapidly with advancing novel analytical technologies, and might fulfill the current lack of genetic indicators availability (Bourlat et al., 2013).

\section{Capability to Address Pressures}

The marine environment is exposed to a variety of different anthropogenic pressures. Some of them are the focus of specific MSFD descriptors (i.e., D2 non-indigenous species, D5 eutrophication, D7 hydrological conditions, D8 contaminants, D9 contaminants in seafood, D10 marine litter, and D11 energy like underwater noise or light). The catalogue here presented contains very few pressure indicators because the main targets were essentially indicators of biological diversity, food webs and seafloor integrity, which are state descriptors sensu MSFD (D1, D4, and D6, Claussen et al., 2011). The few pressure indicators reported relate to the pressure caused by non-indigenous species, or result from the existence of mixed pressure/state requirements within a few MSFD criteria (Berg et al., 2015).

Measuring some types of pressures is fairly self-explanatory but we cannot directly measure something like abrasion, for example. Particle size or topography can contribute to assess abrasion, but those parameters vary with other pressures too and, in such cases, the activity is measured instead (Knights et al., 2013; Smith et al., 2016). An ecosystem-based approach is, therefore, needed, where an improvement of the environmental status requires a combination of measures to control the whole suite of pressures introduced by the full range of human activities that impact the marine ecosystem (Knights et al., 2013). The availability of state indicators capable of capturing signal from an identified pressure(s) can provide direct statistical evidence for the relationship between the activity (e.g., trawling effort, which can be managed) that induces the pressure (e.g., fish removal) and an indicator response (e.g., "Large Fish Indicator," Engelhard et al., 2015).

Therefore, despite focusing on the integrity of the ecosystem, state indicators might still have a more or less evident relationship to anthropogenic pressures (Nõges et al., 2016), even if a direct relationship to one or several pressures is sometimes difficult to prove. This is due to the diversity of pressures, and their cumulative and synergistic effects, that may affect specific ecological characteristics of the ecosystem, and also to the complexity and variability of relationships and feedbacks within the ecosystem itself (Knights et al., 2013; Oesterwind et al., 2016; Smith et al., 2016). For example, the cross-linkages and dependencies between trophic levels and competitors for food and space are too numerous and variable to clearly track the path of chain events (Knights et al., 2013). Nevertheless, several state indicators in the catalogue are sensitive to one or more pressures and can provide powerful insight within specific ecosystem-based management frameworks.

As also expected, most of the state indicators were sensitive to pressures that are predominant across coastal and marine regions, such as "nutrient and organic matter enrichment."
Primary and secondary eutrophication impacts cascade through the whole ecosystem and have consequences on biodiversity, on species and habitats, as well as at the food web and ecosystem level, which is reflected by the number of sensitive indicators. Likewise, the several EU policies such as the Nitrates and the Urban Waste Water Treatment Directives (91/676/EEC; 91/271/EEC) and the WFD have specifically imposed obligations to assess the impacts of the implementation of these regulations, and to demonstrate if there are improvements. For this reason, a number of indicators have been developed to reflect the impacts on various compartments of the ecosystem and many of the existing indicators have been also suggested as suitable for the assessment of the (D5) eutrophication status (Ferreira et al., 2011; Berg et al., 2015). Considering the most predominant sectors of activity in most marine ecosystems (Knights et al., 2013), the five pressures most likely to affect biological diversity and food webs were "interference with hydrologic processes," "introduction of non-synthetic compounds," "changes in siltation," "introduction of synthetic compounds," and "marine litter." Seafloor integrity is mostly menaced by pressures causing "physical loss" and "habitat damage" (e.g., causing fragmentation and changes in connectivity), but also nutrients and other contaminants input will strongly impact benthic communities (e.g., with homogenizing effect) (ICES, 2015b). With an exception for marine litter, the catalogue includes many indicators particularly sensitive and responsive to these pressures.

Recently, Joppa et al. (2016) have found that no global datasets are available for addressing IUCN listed pressures most affecting threatened marine species: "transportation and service corridors" and "human intrusions and disturbance". The catalogue contains indicators that tackle both issues (e.g., "Ballast water treatment indicator," "Trends in pathways of introduction NIS"). This shows that, at least regionally, some data and indicators are available, and that these threats are under the eye of monitoring programs. The remaining IUCN listed threats ("residential and commercial development," "biological and resource use," "invasive and other problematic species") are also covered, to some extent, by indicators in the catalogue that focus, for example, on fisheries and extraction of living resources, impacts on the seabed, trends in NIS and toxic species. "Pollution" issues are poorly covered by specific pressure indicators of the catalogue, since it relates more to contaminants (MSFD D8 and D9), marine litter (MSFD D10), and energy /noise (MSFD D11), which were not the target of our survey.

Conceptual models of the pathways of state change (Smith et al., 2016) suggest that the components of the DPSIR are not mutually exclusive and that biological change can be direct or can follow a series of physical state changes. So, the "P" and the "S" part are a continuum and, therefore, it can be challenging to fit indicators into a single stage within the DPSIR cycle. In a few cases, the information reported in the catalogue was not always enough to clarify whether an indicator was a pressure or state one. The type of data feeding the indicator can also determine its potential role within the framework. For example, "bycatch" indicators provide evidence of damage to non-commercial species (e.g., "by-catch of marine mammals and waterbirds in fishing gears"), and changes in this indicator 
indicate low or increasing pressure. Notwithstanding, changes in the total numbers of organisms affected by by-catch may also allow tracking an increasing trend or a decline of certain species, if long-term data is available.

\section{Limitations of the Catalogue}

Four major limitations of the catalogue were identified and are outlined below together with the implications when submitting queries to the catalogue: (i) heterogeneity in the amount and type of information reported on indicators; (ii) multiple reported indicators; (iii) ambiguity while interpreting fields in the catalogue; and (iv) survey gaps in the catalogue.

Missing (not reported) data, especially if forming a pattern (e.g., limited coverage of a given regional sea or failure to cover a scientific area due to lack of access rather than real lack of available information), might have compromised the robustness of the analyses (e.g., catalogue capabilities and gap analysis), and have some influence on the final recommendations and conclusions drawn out of this catalogue.

When the same indicator was repeatedly reported by more than one contributor or different indicators were reported as unique but are actually based on and conveying essentially the same information, this may lead to some approaches being under- or overrepresented in the catalogue compared to their actual availability (e.g., per geographical area or per biodiversity component). But redundancy in the focus of the indicators, i.e., their scientific basis or ecosystem relevance, does not necessarily mean that the indicators share all their properties.

Due to the great number of contributors to this catalogue, ensuring a common understanding of the fields was not always fully achieved. Heterogeneous information reported compromised the use of several entries in our catalogue, preventing optimum usage of the effort devoted to this compilation and more importantly, reducing the amount of data available for meaningful analysis. This ambiguity in interpreting fields in the catalogue was particularly evident for fields related with, for example, assigning habitat types, establishing links to pressures, and some of the 2010 Commission Decision on criteria and indicators (the latter explored in Berg et al., 2015).

Important gaps identified are in line with those reported by Hummel et al. (2015), namely regarding certain types of indicator approaches (e.g., regarding new molecular-based tools) or specific habitats (e.g., deep-sea habitats) or marine subregions. However, despite of the low prevalence of such indicators in the literature, their poor representation in the database could also be due to failing to engage local or topic-specific experts for the development of the catalogue. As a non-exhaustive catalogue, its content must be taken with caution. Those gaps could have implications on: (a) identifying priorities for the development of new indicators after the gap analysis, and (b) limiting the indicators available for selection and use as the most promising ones under global and local monitoring programs.

\section{Recommendations for Future Improvements of the Catalogue}

The use of the catalogue could be strengthened in the future through further integration with additional quality criteria for indicator selection through a newly developed framework for testing of indicators in a standardized way (Queirós et al., 2016). As much as we filter the database and narrow our choices to indicators most promising within a given context (See example in Box 1), only a standardized approach based on quality analysis criteria, as proposed by Queirós et al. (2016), would allow a proper evaluation, comparison, and final selection of indicators. One of the limitations mentioned before was the danger of redundancy of indicators approaches in the catalogue. However, indicators with a similar focus may differ greatly in other characteristics considered also relevant criteria for evaluating the quality of indicators (Queirós et al., 2016 for a recent review). For example, the acceptability or comprehensibility by the wider public, the complexity of its calculation, or its cost of implementation, may be determinant criteria at the time of selecting indicators. In this sense, the catalogue could benefit from additional or better baseline information on important criteria such as "responsiveness to pressure," or the "possibility to set targets within the indicator response," or "information on the cost-effectiveness of their implementation," to name a few (ICES, 2013, 2015a; Queirós et al., 2016). This would allow an objective evaluation of the quality of the indicator, as detected also by Hummel et al. (2015). Many of the indicators listed as operational did not report any quantitative or qualitative targets or even the existence of those $(n=193)$. It is, therefore, questionable if those indicators are truly operational. Likewise, Hummel et al. (2015) detected that less than half of the indicators selected by EU Member States for biodiversity assessment were operational. This could partially be related to contributors filling the catalogue, who might have refrained from indicating the targets previously used in other policy or environmental contexts. Regardless of the reason behind not reporting targets, it is important to stress that an indicator output should easily be interpreted within a good-bad quality continuum. In a legal and regulatory context, such as, for example, the MSFD, it is crucial to pair indicators with thresholds, although deriving them can often be more challenging than developing the indicators themselves (Rees et al., 2008; Rossberg et al., 2017). Such thresholds are fundamental to observe the accomplishment of legally imposed targets. There are many approaches to setting targets and/or defining reference conditions, whose adequacy will be tightly linked to the context of use of the indicators (Borja et al., 2012). A recent proposal by Rossberg et al. (2017) recognizes that some ecosystems are naturally more resilient than others and proposes an approach where the longest acceptable length of the recovery time is used for setting targets. Regarding the catalogue, and since operational status refers by definition to a fully developed indicator, we expect that information regarding thresholds or targets even if not reported might still be available in the "Sources" cited in the catalogue.

Along these lines, it should also be possible to link the indicator to different components of the DIPSR frameworks or, the more recently proposed, DAPSI $(\mathrm{W}) \mathrm{R}(\mathrm{M})$ framework (Atkins et al., 2011; Wolanski and Elliott, 2015), to allow understanding on how the indicator reflects policy responses and measures impacting the changes in the status. These 
linkages can be demonstrated conceptually, qualitative, or quantitatively (e.g., using models). On the other hand, different types of indicators reflecting Responses, Measures, Drivers and Pressures are needed to demonstrate the effects of management efforts and to advice the policy development (Rapport and Hilden, 2013). As stated earlier, management needs also descriptive indicators, performance indicators, efficiency indicators and total welfare indicators (Smeets and Weterings, 1999).

Another pertinent property of a robust indicator, especially in the context of comprehensive and wide-scale environmental assessment initiatives, is whether the indicators and their data requirements are already covered or are integrating "part of an existing or current ongoing monitoring or data"
(Queirós et al., 2016). The DEVOTool catalogue of marine biodiversity indicators together with the DEVOTES catalogue on marine biodiversity monitoring networks (Patrício et al., 2016) compiled such information, and although it was evident that data are available, it is, nevertheless, difficult to evaluate its adequacy (e.g., Joppa et al., 2016) or account for this feature without a framework for properly ranking and selecting indicators.

Another example of a fundamental but widely neglected criterion is the capability of an indicator to provide "concrete, measurable, accurate, and precise outputs." Our catalogue shows that for the majority of the indicators reported (over 90\%) there was no reference to any measure of confidence or uncertainty associated with their assessment results. Despite the

BOX 1 | DEVOTOOL 0.64 (database version 7) advanced query example: selection of indicators targeting angiosperms, which are particularly responsive to pressures caused by nutrients and organic enrichment. The query includes accessory information on the main attribute of the indicators, their developmental status, and the dpsir stage to which they apply. If monitoring time series are available the respective period is indicated. WFD, Water Framework Directive.

\begin{tabular}{|c|c|c|c|c|}
\hline Indicator name & $\begin{array}{l}\text { Developmental } \\
\text { status }\end{array}$ & DPSIR stage & Main attribute & $\begin{array}{l}\text { Monitoring time } \\
\text { series }\end{array}$ \\
\hline Abundance of bioengineering species & Operational & State & Biotope features & \\
\hline $\begin{array}{l}\text { Accumulated cover of submerged } \\
\text { vascular plants }\end{array}$ & Operational & State & Target groups & \\
\hline Areal extent of eelgrass & Operational & State & Biotope features & $\begin{array}{l}1990-2011 \\
1995-2001\end{array}$ \\
\hline Areal extent of reed belts & Operational & State & Indicator species & \\
\hline $\begin{array}{l}\text { Assessment of macrovegetation in coastal } \\
\text { and transitional waters }\end{array}$ & Operational & State & Biotope features & \\
\hline Beach wrack Macrovegetation Index (BMI) & Operational & State & Target groups & \\
\hline Benthic flora Cheney's ratio index & Under development & State & Community structure & \\
\hline CymoSkew & Operational & State & $\begin{array}{l}\text { Physiological } \\
\text { condition }\end{array}$ & \\
\hline CYMOX Index for lagoons & Operational & State & Biotope features & \\
\hline Depth limit of eelgrass & Operational & State & Biotope features & 2006-2012 \\
\hline Depth limit of spermatophytes & Operational & State & Biotope features & 2004-2012 \\
\hline EPI-Estonian Phytobenthos Index & Operational & State & Biotope features & \\
\hline $\begin{array}{l}\text { POMI-Posidonia oceanica Multivariate } \\
\text { Index }\end{array}$ & Operational & State & Biotope features & \\
\hline POSWARE & Operational & State & Biotope features & \\
\hline Species richness of selected habitats & Operational & State & Community structure & \\
\hline $\begin{array}{l}\text { Strength of conventional bottom-up effect } \\
\text { in marine size spectrum }\end{array}$ & Operational & State & Population ecology & \\
\hline WFD BALCOSIS-Macrophyte index & Operational & State & Biotope features & 2006-2012 \\
\hline WFD British Saltmarsh classification tool & Under development & State & Biotope features & \\
\hline WFD British Seagrass index & Operational & State & Biotope features & \\
\hline WFD Dutch Eelgrass index & Operational & State & Biotope features & \\
\hline WFD ELBO-German Macrophyte index & Operational & State & Biotope features & 2004-2012 \\
\hline WFD German Eelgrass index (intertidal) & Operational & State & Biotope features & $\begin{array}{l}1990-2011 \\
1995-2001\end{array}$ \\
\hline WFD German Saltmarsh index & Operational & State & Biotope features & $2005-2008$ \\
\hline $\begin{array}{l}\text { WFD Polish Assessment system for } \\
\text { coastal and transitional waters using } \\
\text { macrophytes }\end{array}$ & Operational & State & Biotope features & \\
\hline $\begin{array}{l}\text { WFD Romanian Assessment system for } \\
\text { coastal waters using macrophytes }\end{array}$ & Under development & State & Biotope features & \\
\hline $\begin{array}{l}\text { WFD SHWAP_Schleswig-Holstein } \\
\text { Wadden Sea Assessment of } \\
\text { Phytobenthos }\end{array}$ & Operational & State & Biotope features & $1995-2011$ \\
\hline $\begin{array}{l}\text { WFD Valencian Region Method using } \\
\text { Posidonia oceanica }\end{array}$ & Operational & State & Biotope features & \\
\hline
\end{tabular}


recognized importance that the quantification of uncertainty has within an environmental assessment (e.g., Andersen et al., 2010; Chaalali et al., 2015; Uusitalo et al., 2015; Carstensen and Lindegarth, 2016), such procedures are often disregarded during index development and seldom applied as a standardized and sound routine. Examining the propagation of uncertainty from indicators to overall biodiversity assessment (Andersen et al., 2014; Carstensen and Lindegarth, 2016) is of utmost importance to ensure robust assessments within large initiatives (e.g., the MSFD Commission Decision 56 indicators) (Probst and Lynam, 2016). Among the most relevant sources of uncertainty that affect indicators' estimates (Nardo et al., 2008) there are: the choice of sub-metrics or parameters within an indicator, the quality of the underlying data, the approach chosen to deal with missing data, the normalization, weighting, and aggregation procedures. Through our survey, we could observe that: (i) not only this information is usually not available or reported, which by itself is a sign of how the issue is still poorly integrated as a fundamental step in index development and application; but also that (ii) measures of confidence in the results typically cover only few of the sources of uncertainty mentioned above. In this sense, efforts should be focused on increased coverage and standardization of procedures to evaluate sources of uncertainty, to provide better guidance on indicator development, performance evaluation and selection.

Finally, the catalogue could be expanded to further accommodate other types of indicators as, for example, the remaining descriptors of the MSFD, for which several indicators are already included (Berg et al., 2015). The catalogue shows also potential to support selection of indicators that capture the state changes in the natural system that finally result in impacts to the human well-being and to the way we can use the natural resources, i.e., ecosystem services ("I" in DPSIR or "I" and "W" in DAPSI(W)R(M) frameworks; Atkins et al., 2011; Wolanski and Elliott, 2015). In the absence of indicators or metrics specific to ecosystem services (Liquete et al., 2013) the mapping and assessment of ecosystems services could be based on existing approaches. Several indicators in the catalogue have been recently considered useful alternatives for measuring provisioning and regulating marine ecosystem services (Maes et al., 2016) (e.g., catch per unit effort, nutrient load, oxygen concentration, turbidity, $\mathrm{pH}$, primary production, species distribution, extent of marine protected areas). Indicators for provisioning marine ecosystem services depend strongly on fishery statistics, while for regulating services they are based on sea water quality observations or modeling (Maes et al., 2016). The information in the catalogue might reveal other sources of potentially useful and complementary information.

\section{Practical Application in Environmental Assessments}

Recently developed by the DEVOTES project is the Nested Environmental status Assessment Tool (NEAT, http://www. devotes-project.eu/neat, based on Andersen et al., 2014), for assessing the status of marine waters (Borja et al., 2016a). In the
NEAT, the indicators are thematically grouped, assigning them to the corresponding habitats, biodiversity components, spatially defined marine areas and pressures for which they are used (such functionality is ensured through the DEVOTool software presented in this manuscript). The NEAT follows an Ecosystem Approach (Tett et al., 2013), ensuring that all ecosystem features relevant to the assessment are accounted for (Borja et al., 2016a). This NEAT tool, facilitating an indicator-based assessment of marine biological diversity, has been successfully tested across ten case studies in Europe (Uusitalo et al., 2016), and the authors lay down recommendations for best practices while using this customizable NEAT for marine status assessments.

Using multiple lines of evidence during environmental assessments has been common practice for a long time now (e.g., Adams, 2005; Bay et al., 2007). The importance of integrating knowledge from different ecosystem aspects has recently grown with the overall acceptance of the Ecosystem Based Management Approach, and has led to several proposals and recommendations on best practices to integrate multiple indicators and assessment scales (review by Borja et al., 2014). This catalogue will certainly reveal a handy tool for screening and comparing complementary indicators to incorporate into more complex assessments (e.g., Uusitalo et al., 2016).

\section{CONCLUSIONS}

Despite the geographical focus on the European Regional Seas, we consider that this catalogue provides a comprehensive overview of the existing knowledge and advances in the field of ecological assessments, by integrating the major type of indicator approaches currently available and used in regular monitoring and environmental assessment programs, particularly regarding biological diversity, food webs, seafloor integrity and nonindigenous species.

This catalogue supports more effective biodiversity monitoring and further investment in indicators, essential to track and improve the effectiveness of management responses (Butchart et al., 2010). We expect this tool can pave the way to rationalizing the development of indicators, and that weaknesses encountered can set research priorities, promoting a more robust use of indicators within the context of environmental policies and assessment programs.

Moreover the DEVOTool is linked with NEAT that provides a tool to decide upon combination of the different indicators into a holistic assessment of the environmental status. We advocate that these tools linked together will support development toward more coherent assessment of marine ecosystems across the regional seas. Due to their potential to support the use of common indicators and the adoption of standardized approaches across marine conservation initiatives, these tools will certainly facilitate conservation efforts by a wide range of users, such as EU Member States, Regional Sea Conventions, the European Commission, governmental organizations outside the EU, non-governmental organizations, 
scientists, and any person interested in marine environmental issues.

\section{AUTHOR CONTRIBUTIONS}

All co-authors contributed in building the catalogue structure, in the writing process and in discussion of the results. HT, TB, LU, KF, KM, CL, SN, JR, NP, SM, TC, OK, DK, AZ, HV, $\mathrm{MP}$, and SC have contributed with indicators and metadata to the catalogue. HT, TB, LU, and $\mathrm{AH}$ have planned the article. HT, TB, KF, and LU have processed the metadata and performed the analyses. TB has written the catalogue software code.

\section{ACKNOWLEDGMENTS}

We thank J. H. Andersen, A. G. Rossberg, who took valuable time to contribute with indicators to this catalogue. This manuscript is a result of DEVOTES (DEVelopment Of innovative Tools for understanding marine biodiversity and assessing good Environmental Status) project, funded by the

\section{REFERENCES}

Adams, S. M. (2005). Assessing cause and effect of multiple stressors on marine systems. Mar. Pollut. Bull. 51, 649-657. doi: 10.1016/j.marpolbul.2004. 11.040

Agardy, T., Davis, J., Sherwood, K., and Vestergaard, O. (2011). “Taking steps toward marine and coastal ecosystem-based management-an introductory guide," in UNEP Regional Seas Reports and Studies, Vol. 189. 68, (Nairobi).

Andersen, J. H., Dahl, K., Göke, C., Hartvig, M., Murray, C., Rindorf, A., et al. (2014). Integrated assessment of marine biodiversity status using a prototype indicator-based assessment tool. Front. Mar. Sci. 1:55. doi: 10.3389/fmars.2014.00055

Andersen, J. H., Murray, C., Kaartokallio, H., Axe, P., and Molvaer, J. (2010). A simple method for confidence rating of eutrophication status classifications. Mar. Pollut. Bull. 60, 919-924. doi: 10.1016/j.marpolbul.2010. 03.020

Atkins, J. P., Burdon, D., Elliott, M., and Gregory, A. J. (2011). Management of the marine environment: integrating ecosystem services and societal benefits with the DPSIR framework in a systems approach. Mar. Pollut. Bull. 62, 215-226. doi: 10.1016/j.marpolbul.2010.12.012

Bay, S., Berry, W., Chapman, P. M., Fairey, R., Gries, T., Long, E., et al. (2007). Evaluating consistency of best professional judgment in the application of a multiple lines of evidence sediment quality triad. Integr. Environ. Assess. Manag. 3, 491-497. doi: 10.1897/IEAM_2007-002.1

Berg, T., Fürhaupter, K., Teixeira, H., Uusitalo, L., and Zampoukas, N. (2015). The Marine Strategy Framework Directive and the ecosystembased approach-pitfalls and solutions. Mar. Pollut. Bull. 96, 18-28. doi: 10.1016/j.marpolbul.2015.04.050

Birk, S., Bonne, W., Borja, Á., Brucet, S., Courrat, A., Poikane, S., et al. (2012). Three hundred ways to assess Europe's surface waters: an almost complete overview of biological methods to implement the Water Framework Directive. Ecol. Indic. 18, 31-41. doi: 10.1016/j.ecolind.2011.10.009

Borja, Á., Chust, G., Rodríguez, J. G., Bald, J., Belzunce-Segarra, M. J., Franco, J., et al. (2016b). 'The past is the future of the present': learning from longtime series of marine monitoring. Sci. Tot. Environ. 566-567, 698-711. doi: 10.1016/j.scitotenv.2016.05.111

Borja, A., and Dauer, D. M. (2008). Assessing the environmental quality status in estuarine and coastal systems: comparing methodologies and indices. Ecol. Indic. 8, 331-337. doi: 10.1016/j.ecolind.2007.05.004
European Union under the 7th Framework Programme, "The Ocean of Tomorrow" Theme (grant agreement no. 308392), www.devotes-project.eu. MU is partially funded through the Spanish programme for Talent and Employability in $\mathrm{R}+\mathrm{D}+\mathrm{I}$ "Torres Quevedo." AZ is partially funded through the BONUS project BIO-C3 funded jointly by the EU and the Research Council of Lithuania.

\section{SUPPLEMENTARY MATERIAL}

The Supplementary Material for this article can be found online at: http://journal.frontiersin.org/article/10.3389/fmars. 2016.00207/full\#supplementary-material

Supplementary Material S1 | "SuppMatS1_Catalogue_vs7_2016.db"-this file contains the Catalogue of Indicators database version 7; db file opens with DEVOTool $\mathbf{0 . 6 4}$ free software application, downloadable from http://www.devotes-project.eu/devotool/.

Supplementary Material S2 | "SuppMatS2_Categories-definitions.xlsx"this file contains the definitions of indicators' categories adopted in our study within "Main attribute," "Underlying variable type," and "Algorithm type."

Borja, A., Dauer, D. M., and Grémare, A. (2012). The importance of setting targets and reference conditions in assessing marine ecosystem quality. Ecol. Indic. 12, 1-7. doi: 10.1016/j.ecolind.2011.06.018

Borja, A., Elliott, M., Andersen, J. H., Berg, T., Carstensen, J., Halpern, B. S., et al. (2016a). Overview of integrative assessment of marine systems: the ecosystem approach in practice. Front. Mar. Sci. 3:20. doi: 10.3389/fmars.2016.00020

Borja, Á., Marín, S. L., Muxika, I., Pino, L., and Rodríguez, J. G. (2015). Is there a possibility of ranking benthic quality assessment indices to select the most responsive to different human pressures? Mar. Pollut. Bull. 97, 85-94. doi: 10.1016/j.marpolbul.2015.06.030

Borja, A., Prins, T. C., Simboura, N., Andersen, J. H., Berg, T., Marques, J.-C., et al. (2014). Tales from a thousand and one ways to integrate marine ecosystem components when assessing the environmental status. Front. Mar. Sci. 1:72. doi: 10.3389/fmars.2014.00072

Børresen, T. (2013). Blue growth opportunities in sustainable marine and maritime sectors. J. Aquat. Food Product Technol. 22, 217-218. doi: 10.1080/10498850.2013.783748

Bourlat, S. J., Borja, A., Gilbert, J., Taylor, M. I., Davies, N., Weisberg, S. B., et al. (2013). Genomics in marine monitoring: new opportunities for assessing marine health status. Mar. Pollut. Bull. 74, 19-31. doi: 10.1016/j.marpolbul.2013.05.042

Butchart, S. H., Walpole, M., Collen, B., Van Strien, A., Scharlemann, J. P., Almond, R. E., et al. (2010). Global biodiversity: indicators of recent declines. Science 328, 1164-1168. doi: 10.1126/science. 1187512

Cardoso, A. C., Cochrane, S., Doerner, H., Ferreira, J. G., Galgani, F., Hagebro, C., et al. (2010). Scientific Support to the European Commission on the Marine Strategy Framework Directive-JRC Management Group Report. JRC Scientific and Technical Reports.

Carletti, A., and Heiskanen, A. (eds.) (2009). Reports Water Framework Directive Intercalibration Technical Report. Part 3: Coastal and Transitional Waters. JRC Scientific and Technical Reports. EUR 23838 EN/3. European Communities 2009.

Carstensen, J., and Lindegarth, M. (2016). Confidence in ecological indicators: a framework for quantifying uncertainty components from monitoring data. Ecol. Indic. 67, 306-317. doi: 10.1016/j.ecolind.2016.03.002

Chaalali, A., Saint-Beat, B., Lassalle, G., Le Loc'h, F., Tecchio, S., Safi, G., et al. (2015). A new modeling approach to define marine ecosystems foodweb status with uncertainty assessment. Prog. Oceanogr. 135, 37-47. doi: 10.1016/j.pocean.2015.03.012 
Claussen, U., Connor, D., De Vrees, L., Leppänen, J. M., Percelay, J., Kapari, M., et al. (2011). Common Understanding of (Initial) Assessment, Determination of Good Environmental Status (GES) \& Establishment of Environmental Targets (Articles 8, 9 \& 10 MSFD). Luxembourg: European Commission/ICES, 54.

Costanza, R., d’Arge, R., de Groot, R., Farber, S., Grasso, M., Hannon, B., et al. (1997). The value of the world's ecosystem services and natural capital. Nature 387, 253-260.

Costello, M. J., Coll, M., Danovaro, R., Halpin, P., Ojaveer, H., and Miloslavich, P. (2010). A census of marine biodiversity knowledge, resources, and future challenges. PLoS ONE 5:e12110. doi: 10.1371/journal.pone.0012110

Cressey, D. (2016). Talks aim to tame marine Wild West. Nature 532, 18-19. doi: $10.1038 / 532018$ a

Danovaro, R., Snelgrove, P. V., and Tyler, P. (2014). Challenging the paradigms of deep-sea ecology. Trends Ecol. Evol. 29, 465-475. doi: 10.1016/j.tree.2014.06.002

Deter, J., Descamp, P., Ballesta, L., Boissery, P., and Holon, F. (2012). A preliminary study toward an index based on coralligenous assemblages for the ecological status assessment of Mediterranean French coastal waters. Ecol. Indic. 20, 345-352. doi: 10.1016/j.ecolind.2012.03.001

Díaz, R. J., Solan, M., and Valente, R. M. (2004). A review of approaches for classifying benthic habitats and evaluating habitat quality. J. Environ. Manage. 73, 165-181. doi: 10.1016/j.jenvman.2004.06.004

Duffy, J. E., Amaral-zettler, L. A., Fautin, D. G., Paulay, G., Rynearson, T. A., Sosik, H. M., et al. (2013). Envisioning a marine biodiversity observation network. Bioscience 63, 350-361. doi: 10.1525/bio.2013.63.5.8

EEA (2013). Balancing the Future of Europe's Coasts: Knowledge Base for Integrated Management. EEA Report No 12/2013. Copenhagen: European Environment Agency.

EEA (2014). Marine Messages. Copenhagen: European Environment Agency.

EEA (2015). State of Europe's Seas. EEA Report No 2/2015. Copenhagen: European Environment Agency.

Elliott, M. (2002). The role of the DPSIR approach and conceptual models in marine environmental management: an example for offshore wind power. Mar. Poll. Bull. 44, iii-vii. doi: 10.1016/S0025-326X(02)00146-7

Engelhard, G. H., Lynam, C. P., García-Carreras, B., Dolder, P. J., and Mackinson, S. (2015). Effort reduction and the large fish indicator: spatial trends reveal positive impacts of recent European fleet reduction schemes. Environ. Conserv. 42, 227-236. doi: 10.1017/S0376892915000077

Fautin, D., Dalton, P., Incze, L. S., Leong, J.-A. C., Pautzke, C., Rosenberg, A., et al. (2010). An overview of marine biodiversity in United States Waters. PLoS ONE 5:e11914. doi: 10.1371/journal.pone.0011914

Ferreira, J. G., Andersen, J. H., Borja, A., Bricker, S. B., Camp, J., Cardoso da Silva, M., et al. (2011). Overview of eutrophication indicators to assess environmental status within the European Marine Strategy Framework Directive. Estuar. Coast. Shelf Sci. 93, 117-131. doi: 10.1016/j.ecss.2011.03.014

Gatti, G., Bianchi, C. N., Morri, C., Montefalcone, M., and Sartoretto, S. (2015). Coralligenous reefs state along anthropized coasts: application and validation of the COARSE index, based on a rapid visual assessment (RVA) approach. Ecol. Indic. 52, 567-576. doi: 10.1016/j.ecolind.2014.12.026

Geijzendorffer, I. R., Regan, E. C., Pereira, H. M., Brotons, L., Brummitt, N., Gavish, Y., et al. (2015). Bridging the gap between biodiversity data and policy reporting needs: an essential biodiversity variables perspective. J. Appl. Ecol. 53, 1341-1350. doi: 10.1111/1365-2664.12417

Gobert, S., Sartoretto, S., Rico-Raimondino, V., Andral, B., Chery, A., Lejeun, P., et al. (2009). Assessment of the ecological status of Mediterranean French coastal waters as required by the Water Framework Directive using the Posidonia oceanica Rapid Easy Index: PREI. Mar. Pollut. Bull. 58, 1727-1733. doi: 10.1016/j.marpolbul.2009.06.012

GOOS (2016). GOOS Biology and Ecosystems Expert Panel. GOOS BioEco Panel, 6. Gramling, C. (2014). Seafloor mining plan advances, worrying critics. Science 344:463. doi: $10.1126 /$ science. 344.6183 .463

Halpern, B. S., Longo, C., Hardy, D., McLeod, K. L., Samhouri, J. F., Katona, S. K., et al. (2012). An index to assess the health and benefits of the global ocean. Nature 488, 615-620. doi: 10.1038/nature11397

HELCOM (2009). "Biodiversity in the Baltic Sea-An integrated thematic assessment on biodiversity and nature conservation in the Baltic Sea," in Baltic Sea Environment Proceedings No. 116 B (Helsinki).
HELCOM (2013). "HELCOM core indicators: final report of the HELCOM CORESET project," in Baltic Sea Environment Proceedings No. 136 (Helsinki).

Hummel, H., Frost, M., Juanes, J. A., Kochmann, J., Castellanos Perez Bolde, C. F., Aneiros, F., et al. (2015). A comparison of the degree of implementation of marine biodiversity indicators by European countries in relation to the Marine Strategy Framework Directive (MSFD). J. Mar. Biol. Assoc. UK. 95, 1519-1531. doi: $10.1017 /$ S0025315415000235

ICES (2013). Report of the Working Group on the Ecosystem Effects of Fishing Activities (WGECO). Copenhagen: ICES Headquarters.

ICES (2014). Workshop to Develop Recommendations for Potentially Useful Foodweb Indicators (WKFooWI). ICES CM 2014 ACOM:48

ICES (2015a). Report of the Working Group on Biodiversity Science (WGBIODIV). Copenhagen: ICES Headquarters.

ICES (2015b). Report of the Workshop on Guidance for the Review of MSFD Decision Descriptor 6-Seafloor Integrity II (WKGMSFDD6-II). ICES CM 2015 ACOM:50. Denmark: ICES Head-quarters, 133.

Joppa, L. N., O’Connor, B., Visconti, P., Smith, C., Geldmann, J., Hoffmann, M., et al. (2016). Filling in biodiversity threat gaps. Science 352, 416-418. doi: 10.1126/science.aaf3565

Katsanevakis, S., Tempera, F., and Teixeira, H. (2016). Mapping the impact of alien species on marine ecosystems: the Mediterranean Sea case study. Divers. Distrib. 22, 694-707. doi: 10.1111/ddi.12429

Knights, A. M., Culhane, F., Hussain, S. S., Papadopoulou, K. N., Piet, G. J., RaakÃęr, J., et al. (2014). A step-wise process of decision-making under uncertainty when implementing environmental policy. Environ. Sci. Policy 39, 56-64. doi: 10.1016/j.envsci.2014.02.010

Knights, A. M., Koss, R. S., and Robinson, L. A. (2013). Identifying common pressure pathways from a complex network of human activities to support ecosystem-based management. Ecol. Appl. 23, 755-765. doi: 10.1890/12-1137.1

Lee, K. N. (1999). Appraising adaptive management. Conserv. Ecol. 3:3. Available online at: http://www.consecol.org/vol3/iss2/art3/

Levin, L. A., and Le Bris, N. (2015). The deep ocean under climate change. Science 350, 766-768. doi: 10.1126/science.aad0126

Liquete, C., Piroddi, C., Drakou, E. G., Gurney, L., Katsanevakis, S., Charef, A., et al. (2013). Current status and future prospects for the assessment of marine and coastal ecosystem services: a systematic review. PLoS ONE 8:e67737. doi: 10.1371/journal.pone.0067737

Long, R. (2012). "Legal aspects of ecosystem-based marine management in Europe," in Ocean Yearbook (2012), eds A. Chircop, M. L. McConnell and S. Coffen-Smou (The Hague: Hijhoff), 417-484.

Maes, J., Liquete, C., Teller, A., Erhard, M., Luisa, M., Barredo, J. I., et al. (2016). An indicator framework for assessing ecosystem services in support of the EU Biodiversity Strategy to 2020. Ecosyst. Serv. 17, 14-23. doi: 10.1016/j.ecoser.2015.10.023

Marques, J. C., Salas, F., Patrício, J., Teixeira, H., and Neto, J. M. (2009). Ecological Indicators for Coastal and Estuarine Environmental Assessment-A User Guide. UK: WIT Press, 183.

McCauley, D. J., Pinsky, M. L., Palumbi, S. R., Estes, J. A., Joyce, F. H., and Warner, R. R. (2015). Marine defaunation: animal loss in the global ocean. Science 347, 247-254. doi: 10.1126/science. 1255641

Mouillot, D., Graham, N. A. J., Villéger, S., Mason, N. W. H., and Bellwood, D. R. (2013). A functional approach reveals community responses to disturbances. Trends Ecol. Evol. 28, 167-177. doi: 10.1016/j.tree.2012.10.004

Muxika, I., Borja, Á., and Bald, J. (2007). Using historical data, expert judgement and multivariate analysis in assessing reference conditions and benthic ecological status, according to the European Water Framework Directive. Mar. Pollut. Bull. 55, 16-29. doi: 10.1016/j.marpolbul.2006.05.025

Nardo, M., Saisana, M., Saltelli, A., Tarantola, S., Hoffmann, A., and Giovannini, E. (2008). Handbook on Constructing Composite Indicators: Methodology and User Guide. OECD Publishing.

Nõges, P., Argillier, C., Borja, Á., Garmendia, J. M., Hanganu, J., Kode,š, V., et al. (2016). Quantified biotic and abiotic responses to multiple stress in freshwater, marine and ground waters. Sci. Tot. Environ. 540, 43-52. doi: 10.1016/j.scitotenv.2015.06.045

Oesterwind, D., Rau, A., and Zaiko, A. (2016). Drivers and pressures-untangling the terms commonly used in marine science and policy. J. Environ. Manage. 181, 8-15. doi: 10.1016/j.jenvman.2016.05.058 
Ojaveer, H., Jaanus, A., MacKenzie, B. R., Martin, G., Olenin, S., Radziejewska, T., et al. (2010). Status of biodiversity in the Baltic Sea. PLoS ONE 5:e12467. doi: 10.1371/journal.pone.0012467

Patrício, J., Little, S., Mazik, K., Papadopoulou, K., Smith, C. J., Teixeira, H., et al. (2016). European marine biodiversity monitoring networks: strengths, weaknesses, opportunities and threats. Front. Mar. Sci. 3:161. doi: 10.3389/fmars.2016.00161

Pereira, H. M., Ferrier, S., Walters, M., Geller, G. N., Jongman, R. H. G., Scholes, R. J., et al. (2013). Essential biodiversity variables. Science 339, 277-278. doi: 10.1126/science.1229931

Pinto, R., Patricio, J., Baeta, A., Fath, B. D., Neto, J. M., and Marques, J. C. (2009). Review and evaluation of estuarine biotic indices to assess benthic condition. Ecol. Indic. 9, 1-25. doi: 10.1016/j.ecolind.2008.01.005

Piroddi, C., Teixeira, H., Lynam, C. P., Smith, C., Alvarez, M. C., Mazik, K., et al. (2015). Using ecological models to assess ecosystem status in support of the European Marine Strategy Framework Directive. Ecol. Indic. 58, 175-191. doi: 10.1016/j.ecolind.2015.05.037

Pitcher, T. J., Kalikoski, D., Short, K., Varkey, D., and Pramod, G. (2009). An evaluation of progress in implementing ecosystem-based management of fisheries in 33 countries. Mar. Policy 33, 223-232. doi: 10.1016/j.marpol.2008.06.002

Probst, W. N., and Lynam, C. P. (2016). Integrated assessment results depend on aggregation method and framework structure-A case study within the European Marine Strategy Framework Directive. Ecol. Indic. 61(Pt 2), 871-881. doi: 10.1016/j.ecolind.2015.10.040

Probst, W. N., and Stelzenmüller, V. (2015). A benchmarking and assessment framework to operationalise ecological indicators based on time series analysis. Ecol. Indic. 55, 94-106. doi: 10.1016/j.ecolind.2015.02.035

Queirós, A. M., Strong, J. A., Mazik, K., Carstensen, J., Bruun, J., Somerfield, P. J., et al. (2016). An objective framework to test the quality of candidate indicators of good environmental status. Front. Mar. Sci. 3:73. doi: 10.3389/fmars.2016.00073

Rapport, D. J., and Hilden, M. (2013). An evolving role for ecological indicators: from documenting ecological conditions to monitoring drivers and policy responses. Ecol. Indic. 28, 10-15. doi: 10.1016/j.ecolind.2012. 05.015

Rees, H. L., Hyland, J. L., Hylland, K., Mercer Clarke, C. S. L., Roff, J. C., and Ware, S. (2008). Environmental Indicators: utility in meeting regulatory needs. An overview. ICES J. Mar. Sci. 65, 1381-1386. doi: 10.1093/icesjms/fsn153

Rist, L., Felton, A., Samuelsson, L., Sandström, C., and Rosvall, O. (2013). A new paradigm for adaptive management. Ecol. Soc. 18:63. doi: 10.5751/ES-06183180463

Rogers, A. D. (2015). Environmental change in the Deep Ocean. Annu. Rev. Environ. Resour. 40, 1-38. doi: 10.1146/annurev-environ-102014-021415

Rossberg, A. G., Uusitalo, L., Berg, T., Zaiko, A., Chenuil, A., Uyarra, M. C., et al. (2017). Quantitative criteria for choosing targets and indicators for sustainable use of ecosystems. Ecol. Indic. 72, 215-224. doi: 10.1016/j.ecolind.2016.08.005

Rudd, M. A. (2014). Scientists' perspectives on global ocean research priorities. Front. Mar. Sci. 1:36. doi: 10.3389/fmars.2014.00036

Smeets, E., and Weterings, R. (1999). Environmental Indicators: Typology and Overview. Report No. 25, European Environment Agency, Copenhagen, 19.

Smith, C. J., Papadopoulou, K.-N., Barnard, S., Mazik, K., Elliott, M., Patrício, J., et al. (2016).Managing the marine environment, conceptual models and assessment considerations for the European Marine Strategy Framework Directive. Front. Mar. Sci. 3:144. doi: 10.3389/fmars.2016.00144

Smith, C., Papadopoulou, N., Sevastou, K., Franco, A., Teixeira, H., Piroddi, C., et al. (2014). Report on the Identification of Keystone Species and Processes
Across Regional Seas. Deliverable 6.1, 105 pp. +1 Annex. Devotes FP7 Project.

Strong, J. A., Andonegi, E., Bizsel, K. C., Danovaro, R., Elliott, M., Franco, A., et al. (2015). Marine biodiversity and ecosystem function relationships: the potential for practical monitoring applications. Estuar. Coast. Shelf Sci. 161, 46-64. doi: 10.1016/j.ecss.2015.04.008

Tedesco, L., Piroddi, C., Kämäri, M., and Lynam, C. (2016). Capabilities of Baltic Sea models to assess environmental status for marine biodiversity. Mar. Policy 70, 1-12. doi: 10.1016/j.marpol.2016.04.021

Teixeira, H., Berg, T., Fürhaupter, K., Uusitalo, L., Papadopoulou, N., Bizsel, K. C., et al. (2014). Existing Biodiversity, Non-Indigenous Species, Food-Web and SeaFloor Integrity GES Indicators. Deliverable 3.1 198pp +2 Annexes. DEVOTES FP7 Project.

Teixeira, H., Weisberg, S. B., Borja, Á., Ranasinghe, J., A., Cadien, D. Velarde, R. G., et al. (2012). Calibration and validation of the AZTI's Marine Biotic Index (AMBI) for Southern California marine bays. Ecol. Indic. 12, 84-95. doi: 10.1016/j.ecolind.2011.05.025

Tett, P., Gowen, R. J., Painting, S. J., Elliott, M., Forster, R., Mills, D. K., et al. (2013). Framework for understanding marine ecosystem health. Mar. Ecol. Prog. Ser. 494, 1-27. doi: 10.3354/meps10539

Thurber, A. R., Sweetman, A. K., Narayanaswamy, B. E., Jones, D. O. B., Ingels, J., and Hansman, R. L. (2014). Ecosystem function and services provided by the deep sea. Biogeosciences 11, 3941-3963. doi: 10.5194/bg-11-3941-2014

Tittensor, D. P., Walpole, M., Hill, S. L., Boyce, D., Britten, G. L., Burgess, N., et al. (2014). A mid-term analysis of progress toward international biodiversity targets. Science 346, 241-244. doi: 10.1126/science.1257484

Uusitalo, L., Blanchet, H., Andersen, J., Beauchard, O., Berg, T., Bianchelli, S., et al. (2016). Indicator-based assessment of marine biological diversity - lessons from 10 case studies across the European Seas. Front. Mar. Sci. 3:159. doi: 10.3389/fmars.2016.00159

Uusitalo, L., Lehikoinen, A., Helle, I., and Myrberg, K. (2015). An overview of methods to evaluate uncertainty of deterministic models in decision support. Environ. Model. Softw. 63, 24-31. doi: 10.1016/j.envsoft.2014.09.017

Waycott, M., Duarte, C. M., Carruthers, T. J. B., Orth, R. J., Dennison, W. C., Olyarnik, S., et al. (2009). Accelerating loss of seagrasses across the globe threatens coastal ecosystems. Proc. Natl. Acad. Sci. U.S.A. 106, 12377-12381. doi: 10.1073/pnas.0905620106

Wolanski, E., and Elliott, M. (2015). Estuarine Ecohydrology: An Introduction. Amsterdam: Elsevier.

Zampoukas, N., Piha, H., Bigagli, E., Hoepffner, N., Hanke, G., and Cardoso, A. C. (2012). Monitoring for the Marine Strategy Framework Directive: Requirements and Options. JRC Scientific and Technical Reports. Publications Office of the European Union. EUR 25187 EN.

Conflict of Interest Statement: The authors declare that the research was conducted in the absence of any commercial or financial relationships that could be construed as a potential conflict of interest.

Copyright (c) 2016 Teixeira, Berg, Uusitalo, Fürhaupter, Heiskanen, Mazik, Lynam, Neville, Rodriguez, Papadopoulou, Moncheva, Churilova, Kryvenko, Krause-Jensen, Zaiko, Veríssimo, Pantazi, Carvalho, Patrício, Uyarra and Borja. This is an openaccess article distributed under the terms of the Creative Commons Attribution License (CC BY). The use, distribution or reproduction in other forums is permitted, provided the original author(s) or licensor are credited and that the original publication in this journal is cited, in accordance with accepted academic practice. No use, distribution or reproduction is permitted which does not comply with these terms. 